\title{
Ars et ingenium: \\ Demócrito y lo risible \\ en la Agudeza de Gracián
}

Ars et ingenium:

Democritus and the risible in Agudeza by Gracián

\author{
Aurora GonZÁLEZ ROLDÁN \\ Facultad de Filosofía y Letras, Universidad Nacional Autónoma de México \\ ausos.gr@gmail.com
}

\begin{abstract}
Resumen: A la gran riqueza del tópico de Heráclito y Demócrito como símbolo de la mezcla tragicómica, del control de los afectos o de la corriente escéptica, entre otros significados, debe agregarse el de Demócrito, en solitario, como poeta inspirado. Puesto que el Abderita es una fuente de los tópicos platónicos sobre el tema, se convierte en símbolo de la inspiración poética, particularmente en el contexto de la larga disputa sobre la oposición de ars et ingenium. El presente artículo llama la atención sobre la figura preponderante de Demócrito en la Agudeza y arte de ingenio, de Baltasar Gracián, que representa el culmen de la reivindicación del ingenio emprendida en el siglo XVII. Igualmente, señala la relevancia de la base platónica de esta obra, que sobrepasa la repercusión de la retórica bizantina en España - como se considera hasta nuestros días - en relación con su particular postura ante la disputa sobre arte e ingenio.
\end{abstract}

ABSTRACT: It must be added to the richness of Heraclitus and Democritus' subject, as a symbol of the tragicomic blend, of the control of affections or the skeptic tendency, amongst other meanings, that of Democritus, solely, as an inspired poet. Given that the Abderite is a source of the platonic topics on the subject, it turns into a symbol of the poetic inspiration, particularly in the context of the long debate on the opposition between ars et ingenium. This article draws the attention to the dominant figure of Democritus in Agudeza $y$ arte de ingenio by Baltasar Gracián, representing the summit of the wit's claim undertaken in the XVIIth century. Likewise, it points out the importance of the platonic base in this work, that surpasses the repercussion of the byzantine rhetoric in Spain - as considered to this day - in relation to his particular position towards the debate on art and wit.

Palabras Clave: risible; Agudeza; Gracián; Demócrito.

KeYwords: Risible; Agudeza; Gracián; Democritus.

RECIBIDO: 7 de julio de 2015 - ACEPTADO: 30 de septiembre de 2015.

DOI: 10.19130/iifl.nt.2015.33.2.732

En los márgenes de la enorme fortuna del tópico de Heráclito y Demócrito en la literatura y pintura europeas del Renacimiento y en la litera- 
tura áurea española, ${ }^{1}$ me interesa llamar la atención sobre la presencia del abderita, constante a lo largo de siglos, en el tratamiento de un tema que resulta mucho menos observado en relación con su figura, es decir, como símbolo de la inspiración poética.

La perspectiva platónica que anima la Agudeza y arte de ingenio, opacada tal vez por la ausencia de tratados y comentarios renacentistas en torno a las estéticas divergentes de la dominante aristotélica, se hizo acompañar desde antiguo por la figura de Demócrito. El sabio de Abdera fue uno de los precursores de la idea de la inspiración poética, según afirmó Séneca en su conocida "paradoja" que Gracián cita explícitamente en el discurso LXIII de la Agudeza. Como puede constatarse en numerosos textos, desde el De oratore de Cicerón o el Ars poetica de Horacio hasta las Annotationes del Brocense, Demócrito se convierte prácticamente en un símbolo del poeta inspirado, en la larga disputa sobre la oposición de ars et ingenium que emerge también en el tratado graciano. Desde tal punto de vista, Demócrito se alza como una figura preponderante en esta obra que representa el culmen de la reivindicación del ingenio emprendida en el siglo XVII desde terrenos tan disímiles como la práctica teatral y la preceptiva poética.

En el último capítulo de la Agudeza y arte de ingenio, que cierra igualmente su tratado sobre los estilos, Gracián reafirma al ingenio como fuente de los conceptos, al señalarlo como la más importante de las cuatro causas de la agudeza. Refrenda la tensión que existe entre ingenio y juicio, y tras alabar las virtudes del primero sostiene:

Es el ingenio la principal, como eficiente; todas sin él no bastan, y él basta sin todas; ayudado de las demás, intenta excesos y consigue prodigios, mucho mejor si fuere inventivo y fecundo; es perenne manantial de concetos y un contino mineral de sutilezas. Dicen que la naturaleza hurtó al juicio todo lo que aventajó el ingenio; en que se funda aquella paradoja de Séneca, que todo ingenio grande tiene un grano de demencia. ${ }^{2}$

El ingenio, definido así como causa eficiente de la agudeza, introduce la idea del furor poético, que Séneca dice tomar de Aristóteles, pero

\footnotetext{
${ }^{1}$ He estudiado dicho tópico como símbolo de la unión jocoseria en la obra de Baltasar Gracián, de manera amplia, no sólo atendiendo a sus menciones explícitas sino a las consecuencias implicadas en diversos temas y planos en González Roldán 2014.

${ }^{2}$ LXIII, p. 793.
} 
que provendría originalmente de Demócrito. Gracián está aludiendo al De tranquilitate animi, en un pasaje que tuvo una enorme popularidad a partir del Renacimiento y hasta el siglo XVII por lo menos, ${ }^{3}$ y que está estrechamente relacionado con los conocidos versos del Ars poetica (295-305) en los que Horacio, con ironía, hablaba del poeta irreflexivo.

Al ocuparse de la moderación y reposo que debe observarse junto con el esfuerzo y el trabajo como norma de vida, Séneca recuerda a Platón, a Aristóteles y al "poeta griego", sin duda Homero, para aconsejar un cambio de ánimo:

Pero lo mismo en el vino que en la libertad es saludable la moderación. [El espíritu] a veces hay que llevarlo a la euforia y a la libertad y deponer por unos instantes la triste sobriedad. En efecto, si creemos al poeta griego, "a veces también perder el juicio es agradable", a Platón, "en balde llama a las puertas de la poesía el que es dueño de sî", o a Aristóteles, "no ha habido ningún gran talento sin una mezcla de locura": no es posible decir algo extraordinario y por encima de los demás a no ser un espíritu exaltado. Cuando ha menospreciado lo vulgar y corriente y, siguiendo un instinto sagrado, se ha elevado hasta lo sublime, entonces por fin ha cantado algo realmente extraordinario con su boca mortal. No puede alcanzar nada excelso y puesto en lugar escarpado mientras esté en sus cabales: conviene que se salga de lo habitual y se haga notar y muerda las bridas y arrastre consigo a su conductor y lo lleve a donde habría temido remontarse por sí solo. ${ }^{4}$

Esta renuncia a la moderación para ir en busca del arrebato y de lo sublime se enuncia en un pasaje que recomienda el descanso de las arduas tareas, de manera equiparable a la llamada al solaz que hacían los teóricos renacentistas de la risa, siguiendo la Ética de Aristóteles. $\mathrm{Cu}$ riosamente, las prácticas verbales de temas y tonos jocosos conllevaban un descenso hacia el estilo bajo que recomendarían teóricos y autores de tratados de cortesanos como Castiglione, entre otros, para huir de la monotonía de un estilo siempre sostenido.

Por otra parte, las citas de Platón y Aristóteles - o de Demócritoque utiliza Séneca se refieren, es verdad, a la creación poética y al talento intelectual, en un caso y otro; sin embargo este fragmento del cordobés pervivió sobre todo en su formulación más breve, como un aforismo

\footnotetext{
${ }^{3}$ Motto y Clark 1992, pp. 189-200.

${ }^{4}$ Sen., Tranq., VII, X.
} 
o paradoja moral, aunque es posible que no siempre se comprendiera su naturaleza genérica, que lo enlaza con las Paradoxa stoicorum de Cicerón. En este sentido, el aforismo de Séneca podría ser una contestación a la Paradoja V "Omnes stultos insanire", o bien una réplica a la exigencia de los estoicos sobre las cualidades del hombre sabio. ${ }^{5}$ La naturaleza de este género breve no pasó inadvertida para Gracián, pues justamente al evocar la conocida cita de Séneca destaca su naturaleza paradojal. ${ }^{6}$

Además, cabe recordar que las ideas de Platón sobre los distintos tipos de raptos: poético, profético, amoroso, al igual que las de Aristóteles sobre el hombre genial (Problema $X X X$ ), también nutrieron el complejo cultural en torno a la melancolía que la cultura europea construyó a lo largo de los siglos. Así se asoció a una enfermedad y a un temperamento la excelencia intelectual de los hombres. A partir del Renacimiento, con la importante intermediación de neoplatonismo florentino, la unión de la locura o melancolía y la grandeza intelectual cobra nueva fuerza, recordándose frecuentemente el Problema XXX de Aristóteles, pero también de manera recurrente, como Gracián, la paradoja de Séneca: Nullum magnum ingenium sine mixtura dementiae fuit.

Por otra parte, la idea del furor poético de línea retórico-horaciana, difundida en la Edad Media y en el Renacimiento, también tiene su origen en los textos de Platón y Demócrito, independientemente de las ideas aristotélicas. ${ }^{7}$ Platón habría desarrollado en el Fedro (245a) fragmentos del Sobre la poesía de Demócrito de Abdera:

No puede haber un buen poeta sin un enardecimiento de su espíritu y sin un cierto soplo como de locura (17).

${ }^{5}$ Motto y Clarck 1992, p. 192.

${ }^{6}$ Cic., Parad., IV. Sobre la fortuna del género de las paradojas en los Siglos de Oro, que repercute fuertemente en la obra de Gracián, cf. los capítulos 4 y 5 de nuestro trabajo González Roldán 2014.

7 García Berrio 1977, p. 241. Ib., p. 265: “A tal respecto, la base sin duda más operante de su difusión en Italia y en España fue la tradición teórica del platonismo, redescubierto en pureza tras la época de su absoluto reinado en versión horaciana en las retóricas medievales. El tópico del furor, concepción idealista y mitificada del ingenio, constituía con el de la licitud o inmoralidad de la poesía las dos columnas básicas de la doctrina platónica del arte, de muy amplia difusión en Italia; aunque, como en algunas ocasiones ha recordado Weinberg, no llegase nunca a constituir un bloque doctrinal de consistencia y unidad equivalente al horaciano o al aristotélico". 
Lo que escribe un poeta por inspiración divina y por un aliento sacro es sin duda hermoso (18) ${ }^{8}$

Citamos aquí dos de los escasos fragmentos que nos han llegado del sabio de Abdera, fundador junto con Leucipo de Mileto de la escuela atomista, y, según se cree, autor prolífico que abordó materias como la física, la fisiología, la ética y la literatura. ${ }^{9}$ Luis Gil indica que se debe a Demócrito y no a Platón la idea del alma humana como el origen de la creación poética. Sin embargo, el abderita consideraba el alma como mera predisposición natural y atribuía la excelencia de la poesía a la inspiración profética. ${ }^{10}$

En otra larga serie de comentarios, sobre todo dentro de la teoría poética antigua y de los Siglos de Oro, aunque también en tratados médicos, Demócrito representó las dotes naturales de los poetas y oradores. ${ }^{11}$ Frecuentemente se menciona o bien la paradoja de Séneca o bien la teoría democritea de la risa, al tiempo que se contraponen la predisposición natural a la técnica y los saberes aprendidos, al abrigo de la discusión ars versus ingenium de tan larga andadura. ${ }^{12}$

El origen democriteo del furor poético platónico cobra para nosotros renovado interés en virtud de que Gracián a lo largo de todas sus obras contrapone a la acción del juicio las virtudes inventivas y elocutivas del estilo conceptuoso, ligado al ingenio, como causas de hermosura y placer.

Al parecer, se debe a Horacio la originalidad de plantear la dualidad ars versus ingenium, pues antes que él sólo Aristóteles mencionaría apenas el asunto. ${ }^{13}$ Sin embargo, al igual que Platón y Demócrito, el

${ }^{8}$ Dem., frs. 17 y 18.

${ }^{9}$ Bernabé 1988, p. 293.

${ }^{10}$ Gil 1967, pp. 33-37. Sobre la concepción materialista del alma de la cual se desprende la idea de inspiración poética, según Demócrito, cf. el artículo de Pájaro 2004.

${ }^{11}$ Se trata también de una tradición de índole médica, pues la relación del ingenio con lo risible y con la comedia implica la consideración de la teoría fisiológica de la risa, como aparece en el De ridiculis, de Vincenzo Maggi.

${ }^{12}$ García Berrio 1977, pp. 238-330. Sería en Píndaro donde la teoría de la inspiración alcanzaría su mayor prestigio, al igual que en Demócrito, para su posterior expansión, cf. ib., p. 264. Para los antecedentes de la teoría en Demócrito el autor envía al estudio de Tigerstedt.

${ }^{13}$ García Berrio 1977, pp. 238-239: "El Filósofo sólo distingue entre poetas reflexivos e irreflexivos, mientras que la oposición horaciana mencionada atiende a la dife- 
estagirita se limitó a describir la función de la naturaleza del alma en la poiesis, idea que la cristiandad despojaría de su carácter pagano al asimilarla al ingenio, una de las facultades del alma que se insertaba en una jerarquía comunicada con la divinidad. ${ }^{14}$ Aunque al parecer la multitud de comentaristas de Horacio se ocupó en buena medida de los equívocos que implicaba uno de los términos de la dualidad, dividido a su vez en natura et ingenium, la significación de este último no resulta problemática, pues de manera homogénea se admitió como sinónimo de talento natural. Y, según se acepta, evocando esa antigua y un tanto velada asociación del ingenio con la inspiración poética a menudo se menciona a Demócrito, hasta convertirlo prácticamente en un símbolo, incluso con algunos ejemplos en libros españoles:" "Ingenio se toma aquí por el natural, y Genio, que según Demócrito para los versos ayuda más que el arte". ${ }^{16}$

Cabe señalar que la conclusión a la que llega García Berrio sobre el término "ingenio", usado en los textos que analiza, coincide totalmente con la manera en que Gracián lo maneja en la Agudeza. ${ }^{17}$ Pero no hay que olvidar que, según el ideal ciceroniano del vir doctus et facetus - que Gracián tuvo en cuenta en toda su obra-, el otro término del binomio horaciano, el ars, tenía su origen en la retórica clásica. Aristóteles plantea ya el problema de las cualidades humanas indispensables para comenzar la enseñanza de la elocuencia ${ }^{18}$ mientras que Cicerón,

rencia entre los conocimientos adquiridos por estudios $-\mathrm{y}$ los adquiridos o manifiestos por naturaleza".

${ }^{14}$ En el caso de España es necesario tener en cuenta el prestigio de las ciencias médicas, en relación con los temas literarios, y la influencia de ámbitos como la Escuela de Medicina de Alcalá.

15 Es el caso de la cita de Badio Ascencio que aporta García Berrio, ib., p. 462: "Tametsi quaesitum est an carmen laudabile fiat natura. i. Praestanti ingenio ac divite vena natura, an arte id est studio eruditione, et ut visum est Democritus (quod etiam afferit Quintilianus) Bonitati naturae plus concedit, non tum perfectum (Equi solus laudatur) poetam efficiet sine studio".

${ }^{16}$ Morell, Poesías, apud García Berrio 1977, p. 462.

${ }^{17}$ García Berrio 1977, p. 241: "Ingenio, pues, quedaba exaltado como cualidad natural del hombre, entendimiento agente capaz de efectuar la búsqueda selectiva de conceptos en los depósitos de materiales de la inventio que son los loci, tras de haber recorrido las oportunas vías propuestas al talento natural, también éstas radicadas en el mismo ámbito de la inventio".

${ }^{18}$ Rh., 1410, b8. 
en De oratore, retoma la exigencia de una vasta cultura como requisito indispensable para ejercer la elocuencia y discute sobre la preeminencia de la técnica transmisible o el genio innato, precisamente en medio de la discusión sobre lo risible. ${ }^{19}$ También en esta obra se evoca a Platón y a Demócrito en relación con el estilo vehemente. Para Cicerón el orador ha de ser como un actor que experimenta en sí mismo las pasiones que pretende transmitir en el foro:

Con frecuencia, en efecto, he oído que ningún poeta bueno puede surgir - lo cual dicen que por Demócrito y por Platón fue asentado en sus escritos - sin inflamación de ánimo y sin cierta inspiración de un como furor. Por lo cual no queráis estimar que yo mismo, que al decir no quería reproducir o bosquejar viejos sucesos y duelos fingidos de los héroes, ni era actor de una persona ajena, sino autor de la mía, cuando por mí fue Manio Aquilio retenido en la ciudad, hice sin gran dolor las cosas que hice al decir la peroración en aquella causa: viendo afligido, desalentado, acongojado, llevado a peligro sumo a aquel que yo recordaba que fue cónsul, general supremo, condecorado por el Senado, que en los honores de la ovación ascendió al Capitolio, no intenté mover a misericordia a los otros antes de ser yo mismo capturado por la misericordia. ${ }^{20}$

A propósito del manejo de los afectos propios en el orador, la estética renacentista no exigió que los artistas, ni pintores ni escritores, los experimentasen, sino que los infundiesen en el auditorio a partir de los recursos artísticos. ${ }^{21}$ Posteriormente, según los ideales de vida del Barroco, se opta por la renuncia o por el dominio de las pasiones, de manera que el individuo se oculte tras una máscara teatral portada no ya en el foro, para persuadir mediante los afectos, sino en la corte y en la vida, velando artificiosamente el alma y mostrándose, acaso "Heráclito por fuera y Demócrito por dentro", como recomienda Gracián en El Discreto. Sin embargo, la valoración y práctica de lo ingenioso en el Barroco - como

${ }^{19}$ De Or., II, 232-233.

${ }^{20}$ Ib., II, 194-195.

${ }^{21}$ Según Montes Serrano (2006, p. 46), podemos comprobar esto en tratados como el De Pictura de León Battista Alberti, el Tratado de la Pintura de Leonardo da Vinci, o las Vidas de los artistas de Giorgio Vasari, "En todos ellos la expresión artística no es más que un problema técnico - como la invención o la composición - que el artista debe resolver con la mayor pericia posible, independientemente de su situación emocional". 
se sabe llevada a cabo por los creadores más que por los preceptistasabrió los cauces para despojarse de las estrictas reglas del arte clásico, dando cabida a las emociones como causa eficiente de la creación artística, y permitiendo la entrada tanto a lo sublime como a lo deforme.

Como ya hemos señalado, Cicerón considera que lo cómico, en buena medida, busca la persuasión mediante el manejo de los afectos, es decir de lo irracional. Aunque en la admiratio que produce lo risible también esté involucrado un proceso cognoscitivo. Así, vemos que el estudio ciceroniano sobre lo risible verbal se adelanta a la conocida paradoja de Séneca y a la célebre oposición horaciana, al examinar lo risible en una discusión sobre preeminencia de la técnica o el ingenio.

Por su parte, Quintiliano, en el libro VI de su Institutionis oratoriae, que también se ocupa de lo risible, propone la conveniencia y utilidad de que las reglas sean evaluadas por el ingenio. ${ }^{22}$ La exaltación del ingenium que hace Quintiliano merece ser considerada, pues se esperaría que en este libro, de carácter pedagógico, concediera la primacía al arte. ${ }^{23}$ Horacio, quien aparentemente se mantenía en una posición media concediendo igual importancia al arte y a la naturaleza, refuta en su Ars poetica con bastante ironía, una excesiva importancia que, desde su punto de vista, se había otorgado al ingenium representado por Demócrito: ${ }^{24}$

Cree Demócrito que el talento tiene más valor que la pobre técnica y excluye del Helicón a los poetas juiciosos; por eso, buena parte de ellos no se preocupa de cortarse las uñas ni la barba, se aparta a lugares solitarios y evita los baños. Bastará pues, para obtener la fama y el nombre de poeta, con no confiar nunca al barbero Licino una cabeza que no podrían sanar ni las tres Anticiras. ¡Oh, necio de mí, que me purgo de la bilis cuando llega la estación primaveral! ¡Y pensar que nadie podría componer poesías más bellas que las mías! Pero no vale la pena. Desempeñaré, pues, las veces de piedra de afilar que, aunque por sí sola no corta, sirve, no obstante, para volver el hierro más afilado. Enseñaré, sin escribir nada yo mismo, la tarea y la misión del escritor, de dónde surgen los contenidos, qué inspira y forma al poeta, qué conviene y qué no, y adónde conducen la virtud y el error. ${ }^{25}$

\footnotetext{
${ }^{22} \mathrm{VI}, 14$. Aunque el problema se encuentra planteado principalmente en II, 13, y XIX, II.

${ }^{23}$ García Berrio 1977, p. 249.

${ }^{24}$ Cf. la edición de Manuel Mañas Núñez del Arte poética 2006, pp. 72-73.

${ }^{25}$ A. P., vv. 295-308.
} 
El humor que impregna este y otros muchos fragmentos del Ars poetica no impide que, de manera general, Horacio se mantenga en una postura equilibrada ante la oposición ars-ingenium, reconociendo, sin embargo, a partir de la conciencia de su propio prestigio de poeta, la importancia del genio sobre la técnica. A partir de la preeminencia del arte sobre el ingenio que estableció Horacio, se consolida un normativismo estético que se considera asequible mediante el aprendizaje y la sujeción a las autoridades: Platón, Cicerón, Quintiliano, Horacio y, especialmente, Aristóteles, a quien se reconoce como modelo imperfectible. ${ }^{26}$ Durante el medievo, se tendría una dimensión ecléctica y apagada de esta tensión $\mathrm{y}$, al parecer, durante el siglo XVI, los comentadores tanto italianos como españoles no hacen sino parafrasear el fragmento citado de Horacio, sin proponer nada nuevo, a veces anticipándose a la elección de uno de los términos de la dualidad pero por lo general tomándolo como pretexto para introducir alguno de los tópicos más frecuentes. ${ }^{27}$ En este momento de la historia del tópico horaciano, el Brocense también evoca a Demócrito, en una glosa prácticamente literal:

Quia dixit Democritus poetas non fieri, sed ingenio et natura constare: maxima pars poetarum (ne videantur miserae arti aliquid tribuere) secreta petit loca, non barbam, con ungues deponit, non balnea frequentat, sic enim credit facile nomen poetae, sibi comparari: si nunquam capuz (quod alias tota Antycira non purgabit) tonsori expurgandum commiserit. ${ }^{28}$

Otra figura como Vincenzo Maggi habría procedido de manera similar a los comentaristas del Renacimiento, al hilo de la exaltación de la filosofía moral que hace en sus Communes Explanationes, ${ }^{29}$ sin embargo, precisamente en el De ridiculis propone una solución al problema de la disputa ars-ingenium en el plano de lo risible, que juzga de procedencia ciceroniana:

Así pues, ya que la risa depende de la fealdad sin dolor, junto con la admiración, ya puede resolverse claramente aquella gran dificultad citada por Ci-

\footnotetext{
${ }^{26}$ En estos términos García Berrio (1977, p. 289) aporta un resumen de su larga exposición sobre el tópico.

${ }^{27}$ García Berrio 1977, p. 252.

${ }^{28}$ Annotationes, apud García Berrio 1977, p. 52.

${ }^{29}$ Id.
} 
cerón, si lo que importa para excitar la risa proviene de algún arte o más bien de la propia naturaleza. Está claro que, pública y generalmente, se puede transmitir el arte de aquellas cosas, pero conocerlo privada o individualmente de ningún modo es posible. Pues no podemos hacer que nos enseñen a deslizar lo cómico de una sentencia de igual forma que en el arte médica se nos enseña que una enfermedad es combatida por un remedio concreto. Sin lugar a duda en lo cómico conviene tender a la novedad, de la que surge la admiración. ¿Qué admiración puede haber en esto que ha sido inventado y creado por el arte de modo que también puede ser de utilidad para otras cosas? ${ }^{30}$

Maggi plantea que las habilidades del vir facetus no pueden ser enseñadas porque su principio general es el efecto placentero de la novedad. Mientras que uno de los principios generales de toda arte - igual que las ciencias - es su carácter repetible o verificable:

De aquí puede colegirse cuán oscura y ambiguamente trató Cicerón esta cuestión, ya que no dijo de qué dependía la solución de este tema. Pues, ¿qué impide que lo que públicamente se enseña como arte sea en privado obra no de la doctrina, sino de la naturaleza? Así pues, lo ridículo siempre depende en parte del arte, esto es, de lo general, y en parte de la naturaleza, esto es, de lo particular, y aunque no se puede transmitir ningún arte completo sobre esta materia. Y aquí viene bien lo que señala Aristóteles en el libro tercero de la Retórica, hablando del ingenio (Retórica, III, 10, 1410b7-9). El sentido de cuyas palabras es: "decir agudezas es propio de hombres ingeniosos o cultos, sin embargo, educar a éstos es deber de la retórica". Esto es, por sí solos dependen de la naturaleza, pero públicamente son enseñados por el arte. Y puesto que están del lado de la naturaleza, dan lugar a cosas nuevas; por lo que ocasionan también admiración. ${ }^{31}$

Maggi apela a la Retórica de Aristóteles, como hizo Séneca, y, al igual que Cicerón y Horacio, aporta una opinión ecléctica; pero tiene en común con Quintiliano la propuesta de una relación dinámica entre las reglas y la naturaleza, dando a éstas un lugar dentro de la educación general, conocida y repetible, mientras que al ingenio, dentro del dominio de lo natural, atribuye la capacidad de crear novedades y por lo tanto admiración. A reserva de estudiar con mayor profundidad la repercusión en la posteridad de las ideas de Maggi, sobre la risa y la admiración, nos

${ }^{30}$ Maggi, De ridiculis, en Pueo 2001, p. 232.

${ }^{31} \mathrm{Id}$. 
parece un eslabón indispensable de ser señalado en la cadena que, como García Berrio señala, va de una estética equilibrada dentro de la perfección clasicista, cuya regla de oro es ocultar el artificio, al clasicismo que, sin renunciar a las reglas, no tiene empacho en mostrar artificios irrepetibles, nacidos del ingenio. ${ }^{32}$

Las vueltas de los comentarios sobre el tópico ars-ingenium dependían de diversos factores, en parte externos a la discusión teórica literaria. Por ejemplo, la necesidad de difuminar el carácter pagano que suponía la extendida idea de la inspiración poética sería la razón, entre otras, de que ésta se explicara desde los postulados de la filosofía natural - deslindándose así de lo teológico - y que su acción se ciñera a las funciones del ingenio, entendido como potencia anímica. ${ }^{33}$

Quizá se deba también a esta razón, es decir, a que se tiene muy en cuenta un contexto aristotélico y cristiano de las partes del alma que intervienen en la creación poética, que no se haya destacado suficientemente la dimensión platónica de Agudeza y arte de ingenio, introducida como una de las grandes novedades de este tratado, y que surgía además en medio de una escasez de teoría sobre el conceptismo. ${ }^{34}$ La respuesta que se da en España al agotamiento de la estética aristotélica vendría de la mano de las discusiones sobre la oscuridad y la dificultad del estilo, así como de las técnicas del asombro - así lo comprobamos en la extensa descripción de enigmas, misterios y paradojas de la Agudeza-. ${ }^{35}$ Hallamos eco de esta aportación del tratado del jesuita en la creación y los comentarios en torno a la obra del otro gran representante de las novedades conceptistas, Luis de Góngora.

32 García Berrio 1977, p. 60: "Los comentarios se empeñaban directamente en esta cuestión, sin percatarse en general de la enorme importancia que alcanzaba el problema debatido dentro de la evolución contemporánea de las artes equilibradas a las artes descompuestas, del equilibrio de cánones a la distorsión irrefrenable y sistemáticamente inaprensible - al menos hasta Gracián y Tesauro - del ingenio creando la poética de la maravilla; en breve, de la gestación del Manierismo y el alborear del Barroco".

${ }^{33} \mathrm{Al}$ parecer este mismo fin tenían algunas opiniones, por otra parte opuestas, como las de Castelvetro y los italianos Frachetta y Summo, ib., pp. 60-75.

${ }^{34}$ García Berrio 1968, p. 46, señala la reacción que representa el conceptismo ante el agotamiento del aristotelismo renacentista, que trató de imprimir cierta novedad sin apartarse de la imitación, por medio de un principio no aristotélico. Tesauro, en particular, habría intentado autorizar el ingenio con Aristóteles, al tiempo que negaba las aportaciones al respecto de Cicerón y Quintiliano.

${ }^{35}$ Cf. al respecto González Roldán 2014, pp. 138-142. 
A partir del Renacimiento, como hemos comentado, la asimilación de las ideas de inspiración y furor al concepto de ingenium y la idea de ars se va identificando con las técnicas de la imitatio, hechos que podemos ver reflejados en una cesura perceptible en las cuatro causas de la agudeza que enuncia Gracián: el "ingenio" y la "materia", por una parte, y el "ejemplar" y el "arte", por la otra. Así los grandes tratadistas de retórica y poética desde Antonio Lull hasta Alonso López Pinciano, pasando por Salinas, Matamoros, Arias Montano, Herrera o Huarte de San Juan entre otros, tratan los tópicos aledaños al binomio horaciano y aunque admiten la primacía del ingenium para el orador, siguiendo a Cicerón, permanecen anclados al marco horaciano-aristotélico de la creación poética, concediendo lejanamente crédito a los tópicos platónicos. ${ }^{36}$ Sería Carvallo con su Cisne de Apolo quien en 1602 exaltaría al ingenio como una cualidad sine qua non para la creación poética. Carvallo considera al ingenio como una parte del entendimiento relacionado con la "imaginativa" - siguiendo en este punto a Huarte de San Juan - del cual procede la inventio aplicada a la materia poética. Sin embargo, al ingenio como cualidad permanente e innata del poeta debía sumarse otra cualidad, también natural pero accidental y transitoria: la "vena" poética. La originalidad de Carvallo frente a los tratadistas anteriores sería la prioridad sin reservas que concede al ingenio mientras que a las reglas las considera meramente una ayuda. ${ }^{37}$

En cuanto a la importancia del tratado de Carvallo en relación con el de Baltasar Gracián, es de sumo interés el hecho de que identifique al furor poético tanto con la armonía que el poeta infunde a los elementos de su creación - sonido, correspondencia, proporción - como una "desproporción" que recae en el lenguaje empleado por el poeta, independientemente de la armonía lograda en otros niveles del discurso. Es decir, que enuncia los problemas de la primacía de la elocución sobre la invención que planteaban las polémicas gongorinas. ${ }^{38}$ Tal sería el caso de un manuscrito como la Apología en favor de Don Luis de Góngora

${ }^{36}$ La creciente importancia que va cobrando el ingenio en los tratadistas españoles hasta culminar en Carvallo también la señaló Porqueras Mayo 1989; aunque ninguno se acerca a la original formulación graciana según Egido, "Introducción” a Gracián 2005, p. LXII.

${ }^{37}$ Roses Lozano 1990, pp. 34-38.

${ }^{38}$ Id. 
de Francisco Martínez de Portichuelo, acaso seguidor de Carvallo y polemista cercano al círculo de poetas en torno a Lope de Vega que lo sumarían a la defensa de las teorías platónicas que surgen en La Dorotea. ${ }^{39}$ La Apología presenta la particularidad de aplicar extensivamente la teoría platónica de la creación poética a las novedades que traían consigo las Soledades, y, en particular, a propósito de la aparente contradicción entre los verbos "dictar" e "inspirar" que surgen repetidas veces en los grandes poemas gongorinos y que fueron señalados por los críticos del "archipoeta español".

En el marco de las polémicas gongorinas, los partidarios del estilo llano esgrimieron la idea de la "vena" poética para defender la participación de una voz personal en detrimento de la imitación mientras que las voces a favor del cordobés, como Vázquez Siruela, Díaz de Ribas o Martín de Angulo, justificaron mediante la acción del ingenio, asociado con el furor, las creaciones gongorinas, a tal punto que podemos considerar un origen divino de poesía velada o enigmática, que serían sólo discernibles para unos pocos. ${ }^{40}$ Aunque esta postura, por supuesto, sumaba entonces el papel del lector en la añeja polémica.

A propósito de la "vena" poética de Carvallo, conviene recordar que para este teórico representó la posibilidad de remontarse a lo elevado y sublime, por ello y por las razones que a continuación exponemos, aunque sea brevemente, vale la pena indagar en el caso de Gracián el retorno a otras corrientes teóricas no aristotélicas, como la teoría de lo sublime que aportaron los retóricos bizantinos; ${ }^{41}$ pues, fuera de esta línea, históricamente habría que esperar hasta el siglo XVIII para que en otras latitudes volviera a admitirse la unión de la inspiración poética y las grandes realizaciones artísticas.

${ }^{39}$ Como se sabe sería en la polémica sobre el teatro donde tendría lugar la ruptura con la preceptiva aristotélica, que inicia una corriente crítica y da lugar al principio del "gusto" condicionado y definido en cada época, García Berrio 1977, p. 289. La idea de "gusto" encuentra en Gracián uno de sus mejores desarrollos teóricos.

${ }^{40}$ Id. Roses Lozano señala el estudio de Egido (1986) como el fruto de una línea crítica en la que contribuyeron autores como Jones, Parker y García Berrio.

${ }^{41}$ García Berrio admite la componente platónica del conceptismo, aunque no abunda en ello: "Es decir, que en lo que ambas clasificaciones, la de Pellegrini y Gracián, coinciden es en la separación del proceso lógico o intelectual, y del proceso artístico, vieja cuestión de distinción entre las capacidades cognoscitivas y las del 'furor' o la peculiaridad artística" (1968, p. 64). 
No es extraño que, en el discurso que cierra un tratado sobre el ingenio, Gracián califique a esta facultad como la más relevante entre las cuatro causas de la agudeza; así lo refrenda en el resto del discurso que explica las funciones de todas ellas: "Es el ingenio la principal, como eficiente; todas sin él no bastan, y él basta sin todas; ayudado de las demás, intenta excesos y consigue prodigios...". ${ }^{2}$

Aunque a lo largo de toda la Agudeza Gracián califica de sublimes al ingenio, la prudencia, las especies de agudeza, las materias tratadas o al estilo, este uso adjetival parece calificar lo muy apreciado o lo más elevado, en coincidencia con la categoría estética de "lo sublime" como se entiende hoy en día. ${ }^{43}$ Sin embargo, precisamente gracias a la mencionada paradoja de Séneca podemos entender la estrecha unión entre el estilo artificioso - el que cuenta con la mayor densidad de conceptosy la poesía inspirada bajo el furor platónico que conducía a lo sublime.

Entre los elementos que históricamente fueron formando la categoría de "lo sublime" se consideran elementos tan antiguos como la harmonia pitagórica o la catarsis de la tragedia. ${ }^{44}$ Posteriormente, en la discriminación que la literatura patrística hace de los refinamientos formales de la literatura grecolatina en comparación con los libros de la Biblia, san Agustín reflexiona sobre la novedad que trae la unión de la materia elevada y el sermo humilis. ${ }^{45}$ También san Agustín en De doctrina christiana reflexiona sobre la adecuación que ha de hacerse de los genera dicendi heredados de la retórica clásica para su aplicación a la oratoria sagrada que trata, en todo momento, de materias grandes.

${ }^{42}$ Agudeza y arte de ingenio, LXIII.

${ }^{43}$ Aullón de Haro 2006, p. 20: "La idea de lo sublime cabe resumir que se funda en los conceptos griegos de elevación, que es su significado primero en lengua griega, correspondiente al término hýpsos, de grandeza, que es la especificación añadida al primero por Longino, y de lo absolutamente grande una fuerza y un poder que es la moderna discriminación kantiana". Algunos ejemplos de este tratamiento en la Agudeza son: "Una agudeza grave por lo sublime de la materia, y sutil por lo realzado del artificio, es acto digno y proprio del espíritu" (Discurso I); "No es el menor primor desta agudeza dar la salida por una sublime y gustosa semejanza" (Discurso VII); "Siempre ha de ser conforme el término de la asimilación porque, como se escoge para imagen, se requiere en él la propiedad; debe ser sublime en materias graves y muy al caso" (Discurso IX).

${ }^{44}$ Aullón de Haro 2006, pp. 25-27.

45 Vale la pena tener en cuenta la unión de esta res y verbum opuestos, pues hay un paralelo con el estilo artificioso de Gracián — en la senda de Séneca - que era posible componer por medio de un estilo bajo tachonado de conceptos. Al respecto, Aullón de Haro envía al estudio "Sermo humilis", incluido en la obra de Auerbach 1969. 
Otra formulación de lo sublime que supone un conflicto entre los genera dicendi de la retórica tradicional y un sentido trascendente, no espiritual sino estético, es el Peri hýpsos de Dionisio Longino, que supone una reacción contra la abstracción retórica de los tres géneros, tantas veces mencionada, y contra el aparente dominio del orador sobre los afectos. ${ }^{46}$ La idea de lo sublime de Longino tiene la misma base platónica que se remonta a los textos de Demócrito, y que además de otros libros de Platón incluye no sólo la conocida cita del Fedro (245a), sino la totalidad del discurso de Sócrates (Phdr., 244a-252a), donde se propone, según P. Aullón Haro, que

La inspiración poética de Platón representa una elevación como vía extraordinaria y directa de "conocimiento" mediante la cual el poeta supera la limitación de la naturaleza y, consiguientemente, la agónica penuria imitativa del arte. Como es evidente, la inspiración no necesita de la techné. El par ingenium/ars, decisivo en Longino, es amplia creación que procede de Platón. La mayor elevación es la desempeñada por el alma que contempla las Ideas. ${ }^{47}$

Este aspecto de lo sublime platónico está presente en el sustento teórico del concepto graciano que supone una naturaleza cognitiva ${ }^{48}$ al mismo tiempo que poética. Entre otros elementos comunes con Gracián, Longino desarrolla en su tratado el decisivo papel del saber filosófico, la trascendencia de la novedad y la maravilla, y describe cinco causas de la grandeza del estilo:

Son, pues, cinco las fuentes, como uno las podría llamar, más productivas de la grandeza de estilo. Como base común a estas cinco formas se halla el poder de expresión, sin el que no son absolutamente nada. La primera y más importante es el talento para concebir grandes pensamientos... La segunda es la pasión vehemente y entusiasta. Pero estos dos elementos de lo sublime son, en la mayoría de los casos, disposiciones innatas; las restantes, por el contrario, son producto de un arte: cierta clase de formación de figuras (éstas son de dos clases, figuras de pensamiento y figuras de dicción), y, junto a éstas, la noble (1949).

46 Ésta es la opinión de Banfi (1987) en el capítulo "Sobre lo sublime (Longino)"

${ }^{47}$ Pedro Aullón de Haro 2006, p. 39.

${ }^{48}$ Emilio Hidalgo Serna explicó el carácter cognoscitivo, de tipo no racional del “concepto” graciano. Al respecto, cf. también González Roldán 2014, pp. 115 y ss. 
expresión, a la que pertenecen la elección de palabras y la dicción metafórica y artística. La quinta causa de la grandeza de estilo y que encierra todas las anteriores, es la composición digna y elevada. ${ }^{49}$

Aunque este esquema no coincide con el de las cuatro causas eficientes de la agudeza que propone Gracián, llaman la atención las similitudes: al igual que el papel central del ingenium, hay una cesura marcada por la tendencia al arte y al ingenio y un común denominador imprescindible de suficiencia en la expresión verbal. Longino también señala la importancia de la imitación de autores, pero no como ejercicio técnico, sino como las válvulas de escape que proveen de la inspiración y el entusiasmo de aquellos grandes autores.

Aullón de Haro también ha advertido el uso que hace Gracián del término "sublime" como adjetivo e intuye una relación de la agudeza según la define el jesuita con la teoría de lo sublime de Longino, en un marco general de síntesis del carácter técnico aristotélico y de una visión platónica plasmada en la Agudeza y arte de ingenio..$^{50}$ Coincidiendo con esta opinión creemos que la relación que guarda esta obra, con el Peri hýpsos de Longino quizá no se limite a la huella que esta última obra dejó en la retórica de Hermógenes, aclimatada en España por medio de Jorge de Trebisonda y que luego se difundiera en los escolares progymnásmata, ${ }^{51}$ sino que posiblemente se trate también de una postura de orden estético, fundamentada en su común base platónica, y que merece ser considerada para entender la ruptura del sistema estilístico graciano con el sistema tradicional. El jesuita, de manera equiparable a san Agustín y a Longino, formuló un sistema estilístico no sometido al arte de la retórica, sino a un particular régimen o "arte de ingenio" impulsado por una visión estética y filosófica, pero atendiendo profundamente a la filosofía moral. ${ }^{52}$

49 Sobre lo sublime, VIII, 1 ss., ed. de J. García López, 1979.

50 Aullón de Haro 2006, p. 39: “A mi manera de ver cabría sugerir que Gracián intenta una síntesis como alternativa. Entendida así hace más inteligible la posición teórica graciana en su horizonte natural de mayor alcance. Esta posible decisión alternativa como síntesis habría que referirla en algún grado a Pellegrini, que le antecede, y a Tesauro que le subsigue".

${ }^{51}$ Egido, "Introducción” a Gracián 2005, pp. LX y LXII; Egido, "Estudio preliminar” a Gracián 2007, pp. CXXVII-CXXVIII; López Grigera 1994, pp. 59 y 82.

52 Aullón de Haro 2006, p. 51: "Sólo Longino y San Agustín acceden a lo que podemos denominar propiamente categorización poetológica y retórica de lo sublime en 
En Gracián, todo parece apuntar, en efecto, a una postura intermedia, entre las bondades de la contemplación platónica y la eficacia de elementos que no provienen del ingenio, como el juicio y la técnica, pero que no repetía los tópicos acostumbrados de sus antecesores sino por medio de nuevas propuestas. En el discurso final de la Agudeza, al que nos hemos referido (LXIII, De las cuatro causas de la agudeza), Gracián relaciona el ingenio con los afectos, y por lo tanto con la composición natural del hombre, al sostener que va cambiando con las edades. No obstante que ahí se dan la mano conceptos como estilo culto, ingenio, locura y humores, Gracián introduce enseguida una distinción entre el ingenio pronto, de acción rápida y el ingenio lento y de alcance profundo, que finalmente se enlaza con el juicio y con la moralidad. Por otra parte, en otros discursos de la Agudeza se plantean también relaciones concretas entre arte e ingenio, como el discurso LIX, que describe el uso ingenioso de la erudición o característica del estilo culto, por mencionar algunos ejemplos.

Pero no hay que olvidar, en cuanto a la rama representada por el ars, con su prestigio dominante durante la Edad Media y el Renacimiento, que el De lo sublime del Pseudo-Longino - que constituyó uno de los pocos textos que exaltó al ingenio de manera categórica y fue ignorado casi totalmente por los comentaristas del Renacimiento - también se acoge a los presupuestos ciceronianos, estipulando que el orador, para alcanzar la sublimidad, ha de prescindir de todo sentimiento bajo. Este autor, al igual que algunos otros del ámbito español aquí mencionados, como Castiglione y López Pinciano, muestran el alcance de las opiniones ciceronianas en este y otros puntos, al igual que Gracián, quien desarrolla por extenso la imprescindible calidad intelectual y moral del varón ingenioso. En este sentido, otro de los grandes teóricos de la risa, Castelvetro, en sus comentarios a la Poética de Aristóteles hace una jerarquización de las ciencias pertinentes a la poesía y propone un esquema dinámico de la creación literaria, que buscaba, al parecer, conciliar la serie de elementos que se habían ido agrupando en los dos polos de

orden a un sentido de espíritu neoplatónico y por ello mismo, abierto, dentro de los límites conceptuales de su tiempo y su disciplina, a una precategorización de propensión estética... Es decir Longino viene a actuar como un filólogo o un crítico literario y poetólogo de horizonte filosófico; Agustín (en el libro IV de De doctrina cristiana), como un retórico de horizonte teológico". 
la tensión ars-ingenium, de los que hemos mencionado algunos. ${ }^{53} \mathrm{La}$ postura de Gracián no coincide con la de Castelvetro, pues su teoría del concepto daba singular importancia al análisis del sujeto elegido y al establecimiento de las analogías y otras formas de pensamiento que luego serían resueltas de distintas maneras posibles mediante los recursos retóricos y elocutivos.

Como hemos visto, en los textos retóricos clásicos los saberes universales con que debía contar el orador, interpretados más adelante dentro del dominio de las reglas y ajenos a la naturaleza, se subordinaban a la pericia moral del vir bonus. ${ }^{54}$ El tópico del "poeta sabio" terminó siendo una de las líneas principales de la teoría literaria en la Italia del siglo XVI, según muestran los tratados de Fracastoro, Tasso y Scaligero. ${ }^{55}$ En España, las paráfrasis al Ars poetica, de teóricos como Cascales y Falcó, establecieron un contraste entre el ingenio y el poeta sabio, entendiendo por este último, sobre todo, al filósofo moral. ${ }^{56}$

Teniendo en cuenta un panorama así esbozado, recordemos que en el tratado sobre los estilos Gracián destaca la participación del ingenio, sobre todo en el estilo artificioso o conceptuoso, que se convertía en el depositario de sus características. Pero Gracián, en vez de recurrir a Horacio, prefiere citar a Séneca, pues su idea de lo sublime está relacionada, como hemos visto, con la dificultad conceptista y con la oscuridad elocutiva que tenía en el hispanolatino uno de sus principales pilares. Al citar a Séneca y no a Horacio, además, Gracián añade a la disputa ars-ingenium otros de los múltiples tópicos aledaños que hemos mencionado, es decir, la participación de los saberes, pues, en un tratado poético con toda la carga de filosofía moral como es el de Gracián, se acoge al principio aristotélico de la eutrapelia, admitiendo, al hilo de su jerarquización de la naturaleza y la técnica, un cambio de ánimo que equilibra la rectitud del vir bonus dando espacio al descanso, y a la risa. En esta jerarquía que sentaba sus bases en la moral estoica, daba,

${ }^{53}$ Escala que va, en orden ascendente, de los saberes cotidianos, entiéndase sentido común, pasando por las artes instrumentales: gramática y arte versificatoria, hasta llegar a la historia, verdadera y fabulosa, cf. García Berrio 1977, p. 319.

${ }^{54}$ Además de la obra de Cicerón que ya hemos citado al respecto, Quintiliano desarrolla el tema por extenso en Inst., XII, 3.

55 García Berrio 1977, p. 304. Se trata de un señalamiento hecho por Spingard.

${ }^{56} \mathrm{Ib}$., p. 314. De juzgar por estas pocas paráfrasis, en ausencia de comentarios, se concedería gran importancia a la finalidad didáctica de la poesía 
en materia elocutiva, la preeminencia al ingenio, coronado, no obstante, por la técnica:

Es el arte cuarta y moderna causa de la sutileza. Celebre la poesía la fuente de su monte, blasone la agudeza la fuente de su mente. Corone al juicio el arte de prudencia, lauree al ingenio el arte de agudeza. Si toda arte, si toda ciencia que atiende a perficionar actos del entendimiento es noble, la que aspira a realzar el más remontado y sutil bien merecerá el renombre de sol de la inteligencia, consorte del ingenio, progenitora del conceto y agudeza. ${ }^{57}$

Gracián contrapone el intelecto (mente) y la inspiración poética (monte de las musas, se entiende) - es decir la fuente intelectual de la agudeza y la irracional de la poesía - con las artes, de prudencia y de ingenio, que perfeccionan y hacen lucir a sus disciplinas, como si fueran coronas de laurel.

La totalidad de la Agudeza y arte de ingenio - e incluso toda la obra de Gracián - es una suma de contiendas y uniones del arte y del ingenio, como se anuncia ya en el título, pues se compone de descripciones racionales, o discursos, acerca de una producción poética cuyas novedades y maravillas provienen de la novedad y de la espontaneidad. Al reivindicar para sí la originalidad de haber tratado, con recta ratio a la más inasible de las potencias intelectuales, atendiendo también a su vínculo con el furor poético, sin desvincularla nunca del juicio, Gracián reclamaba para sí un sitio de preeminencia entre los teóricos.

\section{BIBLIOGRAFÍA}

ARISTóteles, Retórica, intr., trad. y notas de Arturo Ramírez Trejo, México, Universidad Nacional Autónoma de México, 2002.

AuERBACH, Erich, Lenguaje literario y público en la baja Latinidad y en la Edad Media, Barcelona, Seix Barral, 1969.

Aullón de Haro, Pedro, La sublimidad y lo sublime, Madrid, Verbum, 2006.

BANFi, Filosofia del arte, ed. de Dino Formaggio, Barcelona, Península, 1987.

Cicerón, Marco Tulio, Las paradojas de los estoicos, vrs., intr. y notas de Julio

Pimentel Álvarez, México, Universidad Nacional Autónoma de México, 2000.

${ }^{57}$ LXIII, p. 800. 
Cicerón, Marco Tulio, Acerca del orador, 1-2, intr., trad. y notas de Amparo Gaos Schmidt, México, Universidad Nacional Autónoma de México, 1995.

De Tales a Demócrito. Fragmentos presocráticos, intr., trad. y notas de Alberto Bernabé, Madrid, Alianza Editorial, 1988.

Demetrio, Sobre el estilo, Longino, Sobre lo sublime, ed. de J. García López, Madrid, Gredos, 1979.

EGIDO, Aurora, "La hidra bocal. Sobre la palabra poética en el Barroco", Edad de Oro, 6, 1986, pp. 79-113.

GARCÍA Berrio, Antonio, España e Italia ante el conceptismo, Madrid, CSIC, 1968.

García Berrio, Antonio, Formación de la teoría literaria moderna. 1. Tópica horaciana, Madrid, Cupsa, 1977.

GIL, Luis, Los antiguos y la inspiración poética, Madrid, Guadarrama, 1967.

GonzÁlez Roldán, Aurora, Risa y llanto en los tratados de Gracián. De El Héroe a la Agudeza y arte de ingenio, Valladolid, Publicaciones de la Universidad de Valladolid, 2014.

Gracián, Baltasar, Agudeza y arte de ingenio (ed. facsímil, 1648), intr. de Aurora Egido, Zaragoza, Institución Fernando el Católico, 2007.

Gracián, Baltasar, Arte de ingenio. Tratado de la agudeza (ed. facsímil, Madrid, Juan Sánchez, 1642), intr. de Aurora Egido, Zaragoza, Gobierno de Aragón / Institución Fernando el Católico, 2005.

Gracián, Baltasar, Obras, ed. de Luis Sánchez Laílla, intr. de Aurora Egido, Madrid, Espasa-Calpe, 2001.

Horacio, Quinto Flaco, Arte poética y otros textos de teoría y crítica literarias, trad. y ed. de Manuel Mañas Núñez, Cáceres, Universidad de Extremadura, 2006.

LóPez Grigera, Luisa, La retórica en la España del Siglo de Oro, Salamanca, Universidad de Salamanca, 1994.

Montes Serrano, Carlos, "Baldassar Castiglione y la cultura artística del Cinquecento", en Cicerón y la cultura artística del Renacimiento, Valladolid, Universidad de Valladolid, 2006, pp. 75-78.

MotTo, Ana Lydia y John R. CLARK, "The Paradox of Genius and Madness: Seneca and his influence", Cuadernos de filología clásica: Estudios latinos, núm, 2, 1992, pp. 189-200.

PÁjARo, Carlos Julio, “Poiesis y poesía de Homero a los sofistas”, Eidos, 2, 2004, pp. 8-32.

Porqueras MAYo, Alberto, La teoría poética en el Manierismo y Barroco españoles, Barcelona, Puvill, 1989.

Pueo, Juan Carlos, Ridens et ridiculus. Vicenzo Maggi y la teoría humanista de la risa, Zaragoza, Universidad de Zaragoza, 2001.

Quintiliano, Marco Fabio, Institutionis oratoriae, Libros I-XII, trad. y comentarios de Alfonso Ortega Carmona, Salamanca, Universidad Pontificia, 19972001.

Roses LozAno, Joaquín, "Sobre el ingenio y la inspiración en la edad de Góngora”, Criticón, 49, 1990, pp. 31-49. 
SÉNECA, Lucio Anneo, Diálogos, intr., trad. y notas de Juan Mariné Isidro, Madrid, Gredos, 2000.

Tigerstedt, Eugène N., "Furor poeticus. Poetic inspiration in Greek Literature Before Democritus and Plato", Journal of the History of the Ideas, 31/2, 1970, pp. 163-178.

WeInBerg, Bernard, A History of Literary Criticism in the Italian Renaissance, Chicago, University of Chicago Press, 1961. 
